\title{
Three submicroscopic deletions at the APC locus and their rapid detection by quantitative-PCR analysis
}

\author{
Marina De Rosa ${ }^{1}$, Maria I Scarano ${ }^{1}$, Luigi Panariello ${ }^{1}$, Nicola Carlomagno ${ }^{2}$, \\ Giovanni B Rossi ${ }^{3}$, Alfonso Tempesta ${ }^{3}$, Patrizia Borgheresi ${ }^{4}$, Andrea Renda ${ }^{2}$ and \\ Paola Izzo ${ }^{1}$
}

${ }^{1}$ Dipartimento di Biochimica e Biotecnologie Mediche, CEINGE-Biotecnologie Avanzate, Università di Napoli 'Federico II', Naples

${ }^{2}$ Div. Chirurgia Generale e Trapianti, Università di Napoli 'Federico II', Naples

${ }^{3}$ Endoscopia Digestiva, Ist Nazionale Tumori, Fondazione G Pascale, Naples

${ }^{4}$ Osp. S Giovanni e Ruggi d'Aragona, Salerno, Italy

\begin{abstract}
We describe three unrelated kindreds, affected by familial adenomatous polyposis (FAP), with 5q submicroscopic deletions that encompass the entire adenomatous polyposis coli (APC) gene and the adjacent $D P 1$ gene. In one family the deletion encompasses also the $M C C$ (mutated in colon cancer) gene. Affected members of these families had dysplastic adenomatous polyps and congenital hypertrophy of the retinal pigment epithelium (CHRPE); no individual was affected by mental retardation or facial dysmorphism. The deletions were detected by linkage analysis with several intragenic and closely flanking polymorphic markers and confirmed by a quantitative PCR analysis. This procedure could have an impact on the detection of the molecular defect in FAP patients in whom mutational analysis fails to identify the specific mutation.
\end{abstract}

Keywords: familial adenomatous polyposis; hereditary colorectal cancer; adenomatous polyposis coli gene mutations

\section{Introduction}

Familial adenomatous polyposis (FAP) is an autosomal dominant precancerous condition, caused by germ-line defects in the adenomatous polyposis coli $(A P C)$ gene, a tumour suppressor gene mapped on chromosome $5 \mathrm{q} 21^{1,2}$ FAP patients are affected by hundreds to

Correspondence: Prof. Paola Izzo, Dipartimento di Biochimica e Biotecnologie Mediche, CEINGE-Biotecnologie Avanzate, Università di Napoli 'Federico II', via S Pansini 5, I-80131 Napoli, Italy. Tel: + (39) 81 7463135; Fax: + (39) 81 7463650; E-mail: izzo@dbbm.unina.it

Received 16 November 1998; revised 3 March 1999; accepted 9 March 1999 thousands of colonic and rectal adenomatous polyps that have a high risk of becoming malignant. Frequent extracolonic manifestations are desmoid tumours, epidermoid cysts, osteomas, dental abnormalities, and congenital hypertrophy of the retinal pigment epithelium (CHRPE), which is considered the most common extracolonic manifestation and an early clinical marker of the disease. ${ }^{3}$

The molecular analysis of $A P C$ gene mutations has led to the identification of the disease causing mutation in about $70 \%$ of FAP cases. So far, more than 300 germline mutations have been identified within the $A P C$ gene, most of which are located within exon 15 . These mutations are nonsense $(30 \%)$ or frameshift 
(68\%) mutations leading to a truncated APC protein. ${ }^{4,5}$ Although most $A P C$ gene mutations result in C-terminal truncated proteins, the clinical features of FAP vary to a remarkable extent. It has been suggested that the severity of the disorder, age at cancer onset and number of extracolonic manifestations is related to the size of the truncated APC protein. ${ }^{6}$ In addition to genotype and phenotype heterogeneity, patients with an identical mutation can exhibit phenotype variability, probably due to a modifying locus or environmental factors. $^{6-8}$

Due to the inherent difficulty in detecting gene deletions, interstitial $5 \mathrm{q}$ deletions that encompass the $A P C$ gene have been identified in very few FAP patients. $^{9-16}$ So far, large deletions account for about $2 \%$ of the identified germline mutations. An intragenic APC deletion of $300 \mathrm{bp}$ has recently been described in an Italian polyposis patient. ${ }^{17}$ Phenotype heterogeneity has been observed also in FAP patients with deletion of the entire $A P C$ gene. In some of these patients the colonic manifestations, ie number of polyps, age at onset, and CHRPE, were similar to those observed in classical FAP. ${ }^{9-16,18}$ Mental retardation and/or facial dysmorphism have also been described. ${ }^{10-14}$ Within these cases the frequency of extracolonic manifestations, including subcutaneous lesions, mandibular osteomata and desmoid tumours, are similar to those observed in FAP induced by other types of mutation. $^{14}$

Here we describe three FAP families with $5 q$ submicroscopic deletions encompassing the $A P C$ and $D P 1$ genes. One of these deletions encompasses also the $M C C$ gene, a tumour suppressor gene that is mutated in sporadic colon cancer. ${ }^{19}$ The deletions were detected by linkage analysis using several intra- and extragenic markers and confirmed by a very rapid and sensitive quantitative PCR method.

\section{Materials and Methods}

\section{Patients}

Affected subjects were recruited from health centers in Campania (Southern Italy) and were of Italian origin. The number of polyps, age at cancer onset, mental condition, facial conformation and other extracolonic manifestations were retrieved from hospital records. CHRPE was determined by indirect ophthalmoscopy. In all three families polyposis-affected patients were mentally normal and without facial dysmorphism.

In Family 1 we studied 11 individuals belonging to three generations (Figure 1A). Subject I-1 died from colon carcinoma at the age of 42 , and the proband, subject II-2, had a colon carcinoma at the age of 36 years. Indirect ophthalmoscopic examination showed multiple bilateral CHRPE. Patients II-1, III-2 and III-3 underwent prophylactic proctolectomy at age 48, 32 and 27, respectively. A desmoid tumour of the anterior abdominal wall and a mandibular osteomatous lesion were observed in patients III-2 and III-3, respectively. Subjects III-4, III-5, III-6, IV-1, IV-2 and IV-3 requested molecular diagnosis. Subjects III-4, IV-1, IV-2 and IV-3 (14, 10,12 and 13 years old, respectively) proved to be carriers of the deletion. Only patient III-4 underwent a rectosigmoidoscopy, which revealed a widespread polyposis with more than 100 polyps.

In Family 2 we studied seven individuals (Figure 2A). Subjects I-2 and II-1 died from colon carcinoma at the age of 42 and 30 years, respectively. FAP was clinically diagnosed in subjects II-3 and II-4 at a mean age of 35 years, and in subject II- 5 at the age of 28 years. All three patients underwent total colectomy with ileorectal anastomosis. Subject II-5 developed a kidney clear cell carcinoma, multiple rectal polyps with severe dysplasia and a calcifying epithelioma of Malherbe at the age of 48 years. In all patients, histological examination of the colonic mucosa showed hundreds of dysplastic adenomatous polyps. Patient III-1 had only a few polyps, removed by colonoscopy at the age of 15 , whilst patients III-2 had hundreds of colonic polyps, some in the ascending colon with severe dysplasia; she underwent proctocolectomy at the age of 17 years. All affected individuals in this family had multiple bilateral CHRPE.

In Family 3, without a family history of FAP, the disease was diagnosed in the proband, subject II-2 (Figure 3A), when she was 29 years old. She had profuse colon and gastric polyps with severe dysplasia and she underwent total colectomy with ileorectal anastomosis. In addition to a CHRPE phenotype, she had osteomas and thyroid nodules.

Asymptomatic subjects III-1 and III-2 requested molecular diagnosis.

\section{Genotype Analysis}

Linkage analysis was performed using several flanking and intragenic polymorphic markers. The flanking markers used were the microsatellites D5S82, D5S299, D5S122, D5S134, D5S346, MCC, JW25, ${ }^{20-23}$ and the extragenic restriction fragment length polymorphism (RFLP) EF5.44. ${ }^{24}$ The intragenic markers analysed were the RFLP at the 3 ' untranslated region and those at nucleotide positions 1458, 5037, and $5468 .^{25-27}$

Genomic DNA was extracted from peripheral blood lymphocytes using a salt extraction procedure ${ }^{28} 0.5-1 \mu \mathrm{g}$ of genomic DNA was amplified with $50 \mathrm{pmol}$ of each primer, $200 \mu \mathrm{M}$ of dNTP, $\mathrm{MgCl}_{2} 2.5 \mathrm{~mm}$ and 2.5 units of Taq polymerase enzyme with the reaction buffer supplied with the kit, in a final volume of $100 \mu$ l. The reaction was performed in a 9600 Perkin Elmer PCR apparatus as reported elsewhere. ${ }^{27}$ The extragenic marker EF5.44, the intragenic RFLP at the 3' untranslated region of the gene and that at nucleotide 1458 were analysed by digestion of amplified DNA fragments with Mnl I, Ssp I and Rsa I restriction enzymes, respectively; ${ }^{24-26}$ the intragenic polymorphism at nucleotide 5468 was analysed by the single strand conformation polymorphism (SSCP) of the amplified DNA fragments. ${ }^{27}$ The microsatellite markers mentioned above were analysed by denaturing gel electrophoresis as follows: $15 \mu \mathrm{l}$ of the amplified DNA and $10 \mu \mathrm{l}$ of denaturing loading buffer were denatured at $95^{\circ} \mathrm{C}$ and 
electrophoresed on a 6-8\% polyacrylamide denaturing gel in $1 \times \mathrm{TBE}$ (tris-borate-EDTA) buffer, at 50-40 mAmp, for about $2 \mathrm{~h}$. PCR products were visualised by the silver staining method. ${ }^{29,30}$

\section{Quantitative PCR}

Linkage analysis results were confirmed by a phosphorimager-based quantitative PCR assay. A duplex amplification for each DNA sample analysed, either from individuals of each family or control DNA, was carried out as described. ${ }^{31}$ The two co-amplified products were the fragment $\mathrm{H}$ of exon 15 of the $A P C$ gene, amplified with the primers described by Groden $\mathrm{et} \mathrm{al}^{32}$ and a fragment of the $\beta$-globin gene amplified with primers EA320: ACA CAA CTG TGT TCA CTA GCA and EA116: AAT CAT TCG TCT GTT TCC CA, as internal control of the amplification. The reaction was carried out in a total volume of $50 \mu \mathrm{l}$ containing $200 \mathrm{ng}$ of DNA, 10-20 pmol of each primer, $200 \mu \mathrm{M}$ each of dNTP, $10 \mu \mathrm{Ci}$ of $\alpha{ }^{32} \mathrm{P}$-dATP, $\mathrm{MgCl}_{2} 1.5 \mathrm{~mm}$ and 2.5 units of Taq polymerase with the

A

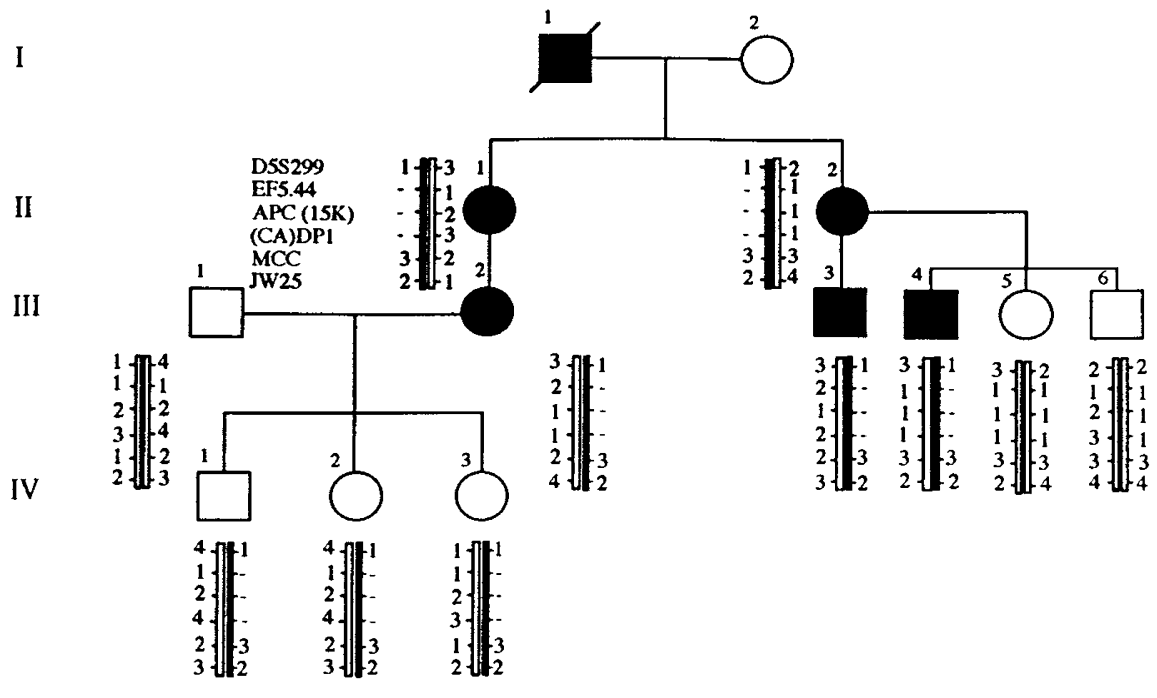

B
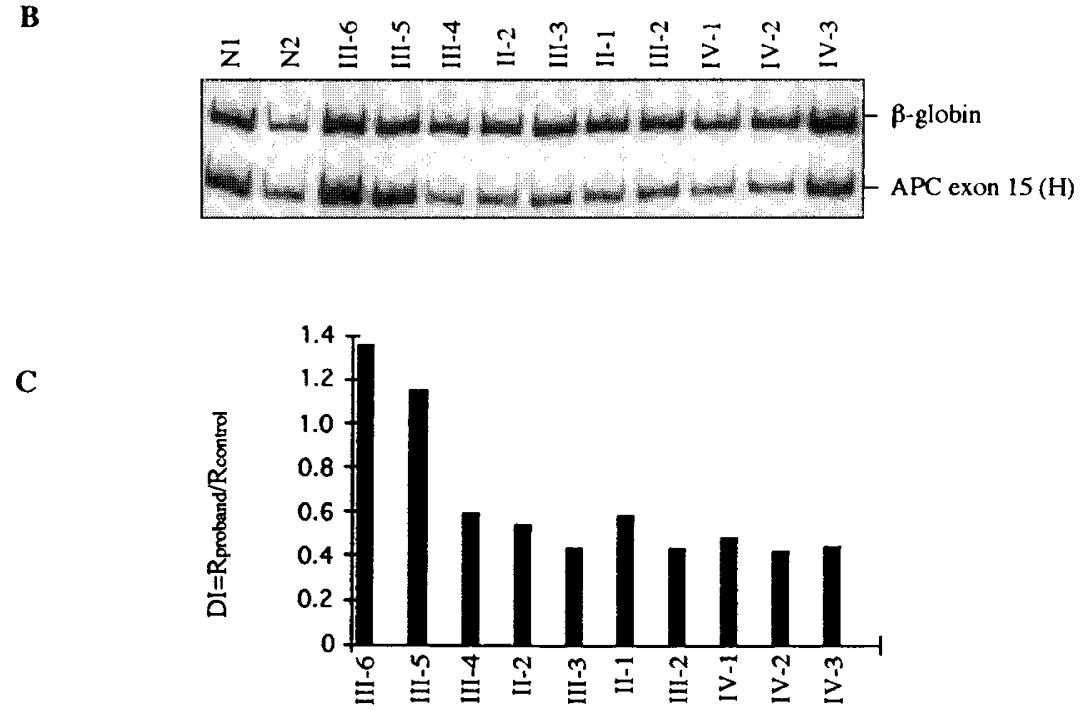

Figure 1 Molecular analysis of Family 1. A: Pedigree and haplotype analysis. Filled symbols: clinically affected FAP subjects; open symbols: family members not affected or asymptomatic carriers. D5S299, EF5.44, APC (15K), D5S346, MCC and JW25 are some of the extra and intragenic markers analysed (see Materials and Methods). The mutated allele is indicated by a thick line. The deleted marker loci are marked by a dash. B: Autoradiography of the quantitative PCR analysis performed in 10 family members and two normal DNA controls (N1 and N2). C: Computer-drawn histogram showing the diagnostic index (DI) calculated using the values obtained from quantitative PCR. 
reaction buffer supplied with the kit. The amplification conditions, performed in a 9600 Perkin Elmer apparatus, were $95^{\circ} \mathrm{C}, 3 \mathrm{~min}$ initial denaturing phase; $95^{\circ} \mathrm{C}, 40 \mathrm{~s} ; 60^{\circ} \mathrm{C}, 20 \mathrm{~s}$; $72^{\circ} \mathrm{C}, 30 \mathrm{~s}$ for 22 cycles; $72^{\circ} \mathrm{C}, 5 \mathrm{~min}$ final extension. For the quantitative amplification of the $M C C$ gene, the MCC microsatellite marker, amplified with the primer described by van Leeuwen et al, ${ }^{33}$ was co-amplified with the $\beta$-globin fragment. The amplification conditions were $95^{\circ} \mathrm{C}, 3 \mathrm{~min}$ initial denaturing phase; $95^{\circ} \mathrm{C}, 40 \mathrm{~s} ; 66^{\circ} \mathrm{C}, 20 \mathrm{~s} ; 72^{\circ} \mathrm{C}, 30 \mathrm{~s}$ for 5 cycles; $95^{\circ} \mathrm{C}, 40 \mathrm{~s} ; 58^{\circ} \mathrm{C}, 20 \mathrm{~s} ; 72^{\circ} \mathrm{C}, 30 \mathrm{~s}$ for 17 cycles; $72^{\circ} \mathrm{C}$, 5 min final extension. $10 \mu$ l of the amplified DNA fragments and $3 \mu \mathrm{l}$ of non-denaturing loading buffer were electrophoresed on a $5 \%$ polyacrylamide non-denaturing gel in $1 \times$ TBE buffer. The gel was dried and exposed with the
GS-250 Molecular Imager (Biorad Laboratories, Hercules, CA, USA) for about $15-18 \mathrm{~h}$. The intensity of the radioactive signals was expressed as pixel density units (PDU). The PDU was measured for each band-containing spot and, after subtraction of the background obtained from a blank area of the same size, the ratio $(R)$ between the value of the spot of the deleted fragment (fragment $\mathrm{H}$ of the $A P C$ gene exon 15) and the value of the spot of the undeleted fragment ( $\beta$-globin gene fragment) was calculated using the formula: $R=$ (spotdeleted -background/(spot undeleted -background). The ratio was calculated with spreadsheet software (Excel 4.0, Microsoft), run on an Apple Macintosh Quadra computer connected to the GS-250 Molecular Imager. The diagnostic index (DI), namely the ratio between the $R$ values in the subject to be

$\mathbf{A}$

I

II

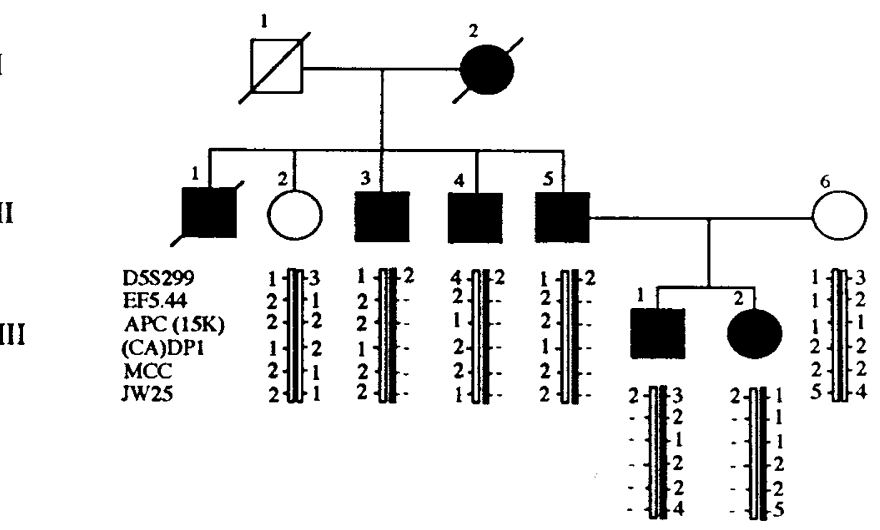

B

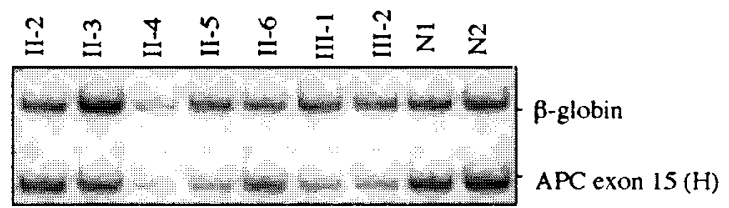

C

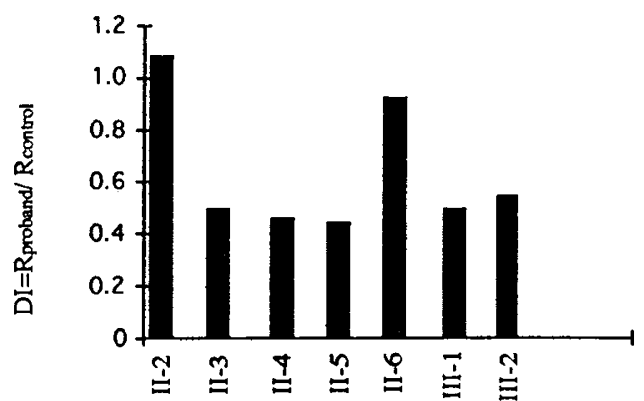

Figure 2 Molecular analysis of Family 2. A: Pedigree and haplotype analysis. Symbols are as reported in Figure 1A. D5S299, EF5.44, $A P C(15 K), D 5 S 346, M C C$ and JW25 are some of the extra and intragenic markers analysed (see Materials and Methods). The deleted marker loci are marked by a dash.B: Autoradiography of the quantitative PCR analysis performed in seven family members and in two normal DNA controls (N1 and N2). C: Computer-drawn histogram showing the diagnostic index (DI) calculated using the values obtained from the quantitative PCR. 
analysed and a normal control, was calculated using the formula: $\mathrm{DI}=R_{\text {propositus }} / R_{\text {normal }}{ }^{31}$

\section{Results}

We describe three submicroscopic deletions of the long arm of chromosome 5 in the distal half of band $5 q 22$, detected by a combination of linkage and quantitative PCR analyses.

In Family 1, the haplotype analysis of the proband II-2 showed loss of heterozygosity for loci EF5.44, APC and D5S346. She was, instead, homozygous for MCC locus and heterozygous for JW25 and D5S299 loci (Figure 1A). She was heterozygous also for the flanking loci D5S134, D5S122 and D5S82 (data not shown). This result indicates that the deletion encompasses loci EF5.44, APC, and D5S346, whereas loci MCC and JW25, telomeric to the $A P C$ gene, and loci D5S134, D5S122, D5S299 and D5S82, centromeric to the $A P C$ gene, are not included within the deletion. The same deleted allele was detected in all affected subjects (II-1, III-2, III-3 and III-4) and in the asymptomatic subjects (IV-1, IV-2 and IV-3). Subjects III-5 and III-6 were not
A

B

II

I

III
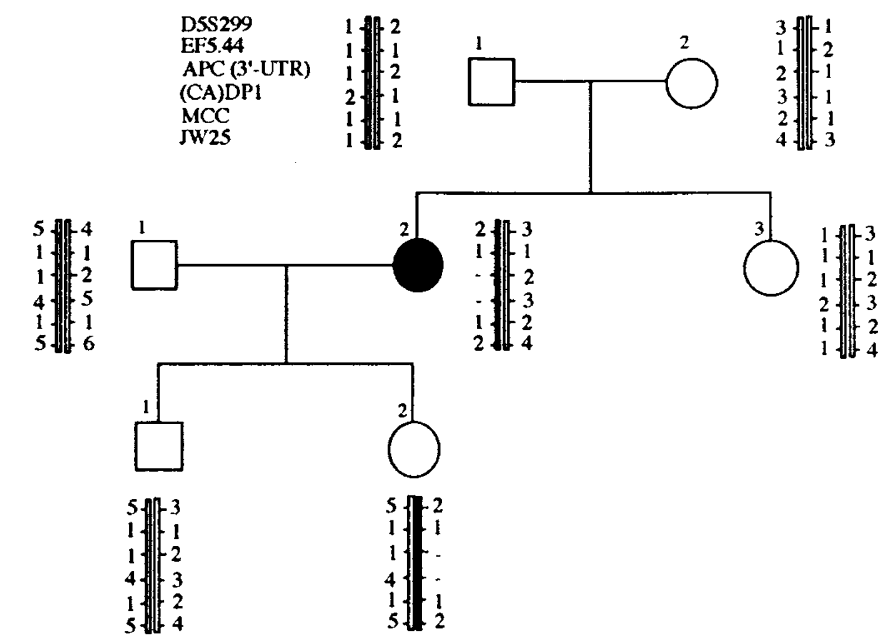

:

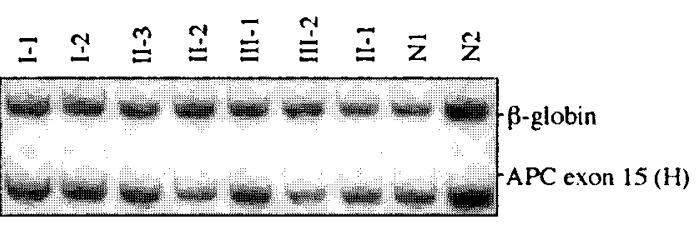

C

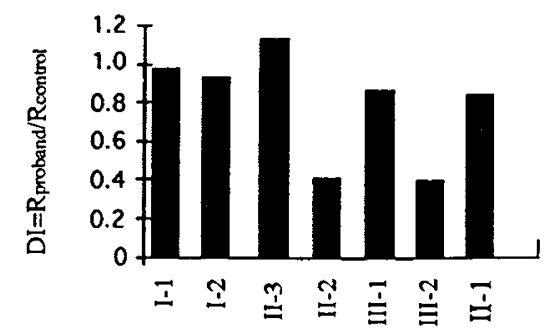

Figure 3 Molecular analysis of Family 3. A: Pedigree and haplotype analysis. Symbols are as reported in Figure 1A. D5S299, EF5.44, APC (3'-UTR), D5S346, MCC and JW25 are some of the extra and intragenic markers analysed (see Materials and Methods). The deleted marker loci are marked by a dash. B: Autoradiography of the quantitative PCR analysis performed in seven family members and in two normal DNA controls (N1 and N2). C: Computer-drawn histogram showing the diagnostic index (DI) calculated using the values obtained from quantitative PCR. 
carriers of the deletion. All the eight carriers of the deletion showed a CHRPE phenotype. Linkage analysis results were confirmed by a phosphorimager-based quantitative PCR assay. The autoradiography of the quantitative-PCR analysis performed in 10 members of Family 1 and in two normal unrelated controls is reported in Figure 1B. The DI was about 0.5 for subjects II-1, II-2, III-2, III-3, III-4, IV-1, IV-2 and IV-3 (Figure 1C). In these subjects linkage analysis had indicated loss of heterozygosity. The DI was about 1 in subjects III-5 and III-6, which by linkage analysis were shown not to be carriers of the deletion.

In Family 2, the haplotype analysis (Figure 2A) of the proband (II-5) showed hemizygosity for loci EF5.44, APC, D5S346 and JW25; he was heterozygous for loci D5S299. He was heterozygous also for loci D5S82, D5S122 and D5S134 (data not shown). The MCC microsatellite was uninformative; however, quantitative PCR analysis for this locus indicated only one allele in the proband and consequently this marker is also included in the deletion. Although large this deletion was not detectable by cytogenetic analysis. The same deleted allele was found in patients II-3, II-4, III-1 and III-2. In this family the deletion encompasses loci EF5.44, APC, D5S346, MCC and JW25, whilst loci D5S82, D5S299, D5S122 and D5S134 are outside the deletion. Figure $2 \mathrm{~B}$ shows the autoradiography of the quantitative PCR performed in seven members of this family. The DI (Figure 2C) was about 0.5 for subjects II-3, II-4, II-5, III-1 and III-2, in which linkage analysis had indicated loss of heterozygosity; the DI was about 1 for subject II-2, diagnosed as healthy by linkage analysis.

In Family 3, the haplotype analysis (Figure 3A) revealed that the proband (subject II-2) was hemizygous for markers APC and D5S346, and heterozygous for markers D5S82, D5S299, MCC and JW25. Markers D5S122, D5S134 and EF5.44 were uninformative. These data indicated that she was carrier of a deletion involving loci APC and D5S346. Her parents, subjects I-1 and I-2, and her sister, subject II-3, were heterozygous for almost all loci analysed, and therefore they were not carriers of the deletion. These data indicate that in Family 3 the deletion was a de novo mutation that had arisen in the paternal germline. Subject III-1 showed a normal haplotype, whilst subject III-2, a 9-year-old child, still asymptomatic, inherited the deleted chromosome from her mother. Figure 3B shows the quantitative PCR analysis of seven members of this family. The DI was about 0.5 for subjects II-2 and III-2, and about 1 for the other family members (Figure 3C).

\section{Discussion}

Detection of the APC gene deletions could explain some of the FAP cases in which direct analysis of the $A P C$ gene fails to detect the specific mutations. Using linkage and quantitative-PCR analysis we identified three submicroscopic deletions that encompass the APC locus in three unrelated FAP families.

In recent years we have studied 18FAP families and the disease-causing mutations were identified in 12 families $(67 \%)$; nine of these show frameshift mutations (50\%) within exons 5, 14 and 15 of the APC gene gu,35 $^{34}$ and three show submicroscopic deletions (about 17\%) (this work). Apart from one frameshift mutation, the 3185delAA that leads to an attenuated phenotype, all other mutations gave rise to a classical or aggressive phenotype $^{34,35}$ (and this work). In the remaining six families $(33 \%)$, the mutational analysis failed to identify the disease-causing mutation and the quantitative PCR analysis excluded the presence of large deletions. A possible explanation is that mutations are located in a region of the gene (introns or promoter) not investigated or that other gene loci are responsible for the increased colorectal cancer risk in these families.

To date, the majority of identified FAP-causing mutations within the $A P C$ gene are those leading to truncated APC products, ${ }^{36}$ whereas deletions of the APC locus have been reported to account for about $2 \%$ of germline APC mutations. ${ }^{17}$ Most of these are cytogenetically visible interstitial deletions of chromosome 5 involving the APC locus. ${ }^{15}$ The quantitative PCR method we used may explain the higher percentage (about 17\%) of deletions found. This quantitativePCR procedure, devised originally for the rapid direct diagnosis of $\mathrm{BMD} / \mathrm{DMD}$ carrier status, ${ }^{31}$ proved to be an easy, rapid and robust method for the 'gene dosage' at the altered APC locus, very useful in detecting gene deletions not long enough to be cytogenetically visible.

Although the wealth of data on APC mutations has greatly contributed to the knowledge of APC protein structure function and of genotype-phenotype correlations, the mechanisms of APC-driven tumorigenesis are not yet fully understood. A 'classical' FAP phenotype is associated with truncating mutations between codon 169 and $1600,{ }^{4}$ a cluster of these, delimited by residues 1250 and 1469 , leading to a 'profuse' form with more 
than 5000 polyps. ${ }^{37}$ Since truncated APC proteins can associate with the wild type protein, a putative dominant-negative mechanism of action has been invoked for these mutations.

Attenuated forms of FAP, the AAPC phenotype, characterised by fewer polyps and a later onset age, have been found associated with mutations at the extreme 5' end or in the 3' part of the $A P C$ gene, beyond codon 1597. ${ }^{7,38-41}$ Mutations at the $5^{\prime}$ end of the $A P C$ gene are predicted to result in extremely short and presumably unstable truncated proteins. Consequently, these mutations might act as a null allele. On the other hand, chain-terminating mutations at the $3^{\prime}$ end of the gene, beyond codon 1597, are predicted to result in relatively large truncated proteins. It has been suggested that these large truncated proteins might retain a residual activity that gives rise to an attenuated phenotype. ${ }^{38}$ However, western immunoblot analysis of lymphoblastoid cell lines derived from patients bearing mutations beyond codon 1597 failed to detect truncated polypeptides and showed only the wild type protein. ${ }^{40,41}$ This led to the suggestion that also mutations at the $3^{\prime}$ end of the gene act as a 'null allele'. Very recently, in tumours from patients who carry an inherited AAPC allele, a lower frequency of loss of heterozygosity of APC alleles compared with tumours from patients who carry an FAP allele has been found. ${ }^{42}$ This finding prompted the suggestion that AAPC alleles may have a residual activity that modulates the spectrum and frequency of mutations leading to adenoma formation. ${ }^{42}$ Taken together, these observations indicate that more data, particularly at the level of APC protein functional domains, are needed to address the complicated issue of genotype-phenotype correlations.

The phenotype associated with allele deletions of the whole $A P C$ gene is not clearly defined. Allele deletions of the APC locus should result in a $50 \%$ deficiency of the normal APC protein. Therefore, these FAP patients represent the natural human model with a 'null allele' for the $A P C$ gene. Our results, in agreement with most studies, indicate that patients with germline APC deletions show a 'classical' FAP phenotype with more than 100 adenomatous polyps, presence of CHRPE, and onset age of about $25-35$ years. ${ }^{10,11,13,15,18}$ This indicates that the 'null allele' in patients bearing $A P C$ gene deletions and dominant negative alleles are equivalent in respect of their phenotypic consequences. However, the putative dominant-negative mechanism cannot be applied to the 'classical' phenotype observed in patients bearing large deletions. At the present state of knowledge, the classical phenotype in these patients may be explained mostly by haploinsufficiency.

Finally, it has been suggested that the size of the deletion might contribute to the development of other phenotypic manifestations, such as mental retardation and facial dysmorphism. ${ }^{14}$ To our knowledge, the patients analysed in this study were mentally normal and none showed facial dysmorphism. Interestingly, Family 2 displays intrafamilial phenotypic variability: among affected subjects colonic disease manifestations were expressed at very different ages and the number of polyps ranged from few in some patients to hundreds in others; extracolonic manifestations, ie kidney carcinoma and calcifying epithelioma, were present in one of these patients. These data support the notion that other genetic and/or environmental factors could play an important role in the penetrance of the disease.

\section{Acknowledgements}

We thank F Costanzo for critical reading of the manuscript We are indebted to Jean Gilder for editing the text. This work was supported by grants from MURST (PRIN'97) and CNR (target project: Biotechnology), Rome; from AIRC (target project: Tumori ereditari del colonretto), Milan.

\section{References}

1 Bodmer W, Bailey C, Bodmer $\mathrm{J}$ et al: Localization of the gene for familial adenomatous polyposis on chromosome 5. Nature 1987; 328: 614-616.

2 Leppert M, Dobbs M, Scambler P et al: The gene for familial polyposis coli maps to the long arm of chromosome 5. Science 1987; 238: 1411-1443.

3 Rustgi AK: Hereditary gastrointestinal polyposis and nonpolyposis syndromes. $N$ Engl J Med 1994; 25: 1694-1702.

4 Nagase H, Nakamura Y: Mutations of the APC (adenomatous polyposis coli) gene. Hum Mutat 1993; 2: 425-434.

5 Béroud C, Soussi T: APC gene: database of germline and somatic mutations in human tumors and cell lines. Nucl Acids Res 1996; 24(1): 121-124.

6 Kinzler KW, Vogelstein B: Lessons from hereditary colorectal cancer. Cell 1996; 87: 159-170.

7 Scott RJ, van der Luijt R, Spycher M et al: Novel germline APC gene mutation in a large familial adenomatous polyposis kindred displaying variable phenotypes. Gut 1995; 36: 731-736.

8 Dobbie Z, Heinimann K, Bishop DT, Muller H, Scott RJ: Identification of a modifier gene locus on chromosome 1p35-36 in familial adenomatous polyposis. Hum Genet 1997; 99: 653-657.

9 Herrera L, Kakati S, Gibas L, Pietrzak E, Sandberg AA: Brief clinical report: Gardner syndrome in a man with an interstitial deletion of 5q. Am J Med Genet 1986; 25 473-476. 
10 Kobayashi T, Narahara K, Yokoyama Y et al: Gardner syndrome in a boy with interstitial deletion of the long arm of chromosome 5. Am J Med Genet 1991; 41: 460-463.

11 Cross I, Delhanty J, Chapman P et al: An intrachromosomal insertion causing 5q22 deletion and familial adenomatous polyposis coli in two generations. J Med Genet 1992; 29: $175-179$.

12 Hodgson SV, Coonar AS, Hanson PJV et al: Two cases of $5 \mathrm{q}$ deletions in patients with familial adenomatous polyposis: possible links with Caroli's disease. J Med Genet 1992; 30: 369-375.

13 Lindgren V, Bryke CR, Ozcelik T, Yang-Feng TL, Francke $\mathrm{U}$ : Phenotypic, cytogenetic, and molecular studies of three patients with constitutional deletions of chromosome 5 in the region of the gene for familial adenomatous polyposis. Am J Hum Genet 1992; 50: 988-997.

14 Barber JCK, Ellis KH, Bowles LV et al: Adenomatous polyposis coli and a cytogenetic deletion of chromosome 5 resulting from a maternal intrachromosomal insertion. $J$ Med Genet 1994; 31: 312-316.

15 Van der Luijt RB, Tops CMJ, Meera Kan $\mathrm{P}$ et al: Molecular, cytogenetic and phenotypic of a constitutional reciprocal translocation $\mathrm{t}(5 ; 10)(\mathrm{q} 22 ; \mathrm{q} 25)$ responsible for familial adenomatous polyposis in a Dutch pedigree. Genes Chrom Cancer 1995; 13: 192-202.

16 Mandl M, Caspari R, Jauch A et al: Familial adenomatous polyposis: a submicroscopic deletion at the APC locus in a family with mentally normal patients. Hum Genet 1996; 97: 204-208.

17 Gismondi V, Bafico A, Biticchi R et al: 310 Basepair APC deletion with duplication of breakpoint (4394ins15del310) in an Italian polyposis patient. Hum Mutat 1998; 1: S220-S222.

18 Olschwang S, Tiret A, Laurent-Puig P, Muleris M, Parc R, Thomas G: Restriction of ocular fundus lesions to a specific subgroup of APC mutations in adenomatous polyposis coli patients. Cell 1993; 75: 959-968.

19 Kinzler KW, Nilbert MC, Vogelstein B: Identification of a gene located at chromosome $5 \mathrm{q} 21$ that is mutated in colorectal cancer. Science 1991; 251: 1366-1370.

20 Eckert WA, Jung C, Wolff G: Presymptomatic diagnosis in families with adenomatous polyposis using highly polymorphic dinucleotide CA repeat markers flanking the APC gene. J Med Genet 1994; 31: 442-447.

21 Breukel C, Tops C, van Leeuwen $\mathrm{C}$ et al: AT repeat polymorphism at the D5S122 locus tightly linked to adenomatous polyposis coli (APC). Nucl Acids Res 1991; 19(23): 6665.

22 Koorey DJ, McCaughan GW, Trent RJ, Gallagher ND: Dinucleotide repeat polymorphism at the D5S134 locus linked to the adenomatous polyposis coli (APC) gene. Hum Mol Genet 1992; 1(8): 655.

23 Spirio L, Joslyn G, Nelson L, Leppert M, White R: A CA repeat $30-70 \mathrm{~KB}$ downstream from the adenomatous polyposis coli (APC) gene. Nucl Acids Res 1991; 19(22): 6348.

24 Olschwang S, Fabre R, Laurent-Puig P et al: Detection by DGGE of a new polymorphism closely linked to the adenomatous polyposis coli region. Hum Genet 1992; 88: $658-660$
25 Heighway J, Hoban PR, Wyllie AH: Ssp1 polymorphism in sequence encoding $3^{\prime}$ untranslated region of the APC gene. Nucl Acids Res 1991; 19: 6966.

26 Kraus C, Ballhausen WG: Two intragenic polymorphisms of the APC-gene detected by PCR and enzymatic digestion. Hum Genet 1992; 88: 705-706.

27 De Rosa M, Scarano MI, Panariello L, Salvatore F, Izzo P: A new MboII polymorphism in exon 15 of the human adenomatous polyposis coli gene. Clin Genet 1998; 53(4): 315-316.

28 Miller SA, Dykes DD, Polesky HF: A simple salting out procedure for extracting DNA from human nucleated cells. Nucl Acids Res 1988; 16: 1215.

29 Stella A, Lonoce A, Resta N et al: Familial adenomatous polyposis: identification of a new frameshift mutation of the APC gene in an Italian family. Biochem Biophys Res Commun 1992; 184(3): 1357-1363.

30 Budowle B, Chakraborty R, Giusti AM, Eisenberg AJ, Allen RC: Analysis of the VNTR locus D1S80 by the PCR followed by high-resolution PAGE. Am J Hum Genet 1991; 48: 137-144.

31 Pastore L, Caporaso MG, Frisso G et al: A quantitative polymerase chain reaction (PCR) assay completely discriminates between Duchenne and Becker muscular dystrophy deletion carriers and normal females. Mol Cell Probe 1996; 10: 129-137.

32 Groden J, Thliveris A, Samowitz W et al: Identification and characterization of the familial adenomatous polyposis coli gene. Cell 1991; 66: 589-600.

33 van Leeuwen $\mathrm{C}$, Tops $\mathrm{C}$, Breukel $\mathrm{C}$ et al: CA repeat polymorphism within the MCC (mutated in colorectal cancer) gene. Nucl Acids Res 1991; 19(20): 5805.

34 Scarano MI, De Rosa M, Gentile M et al: Identification of three novel germ-line mutations in the APC gene. Hum Mutat 1997; 9: 191-193.

35 Scarano MI, De Rosa M, Panariello L et al: Familial adenomatous polyposis coli: five novel mutations in exon 15 of the adenomatous polyposis coli (APC) gene in italian patients. Hum Mutat, Mutation in Brief 1999; No.225.

36 Smith KJ, Johnson KA, Bryan TM et al: The APC gene product in normal and tumor cells. Proc Natl Acad Sci USA 1993; 90: 2843-2850.

37 Nagase H, Miyoshi Y, Horii A et al: Correlation between the location of germ line mutations in the APC gene and the number of the colorectal polyps in familial adenomatous polyposis patients. Cancer Res 1992; 52: 4055-4057.

38 Friedl W, Meuschel S, Caspari R et al: Attenuated familial adenomatous polyposis due to a mutation in the $3^{\prime}$ part of the APC gene. A clue for understanding the function of the APC protein. Hum Genet 1996; 97: 579-584.

39 Spirio L, Olschwang S, Groden J et al: Alleles of the APC gene: an attenuated form of familial polyposis. Cell 1993; 75: $951-957$

40 van der Luijt R, Khan PM, Vasen HSA et al: Germline mutations in the $3^{\prime}$ part of APC exon 15 do not result in truncated proteins and are associated with attenuated adenomatous polyposis coli. Hum Genet 1996; 98 $727-734$. 
41 Eccles DM, van der Luijt R, Breukel C et al: Hereditary desmoid disease due to a frameshift mutation at codon 1924 of the APC gene. Am J Hum Genet 1996; 59: 1193-1201.
42 Spirio L, Samowitz W, Robertson J et al: Allele of the APC modulate the frequency and classes of mutations that lead to colon polyps. Nat Genet 1998; 20: 385-388. 